
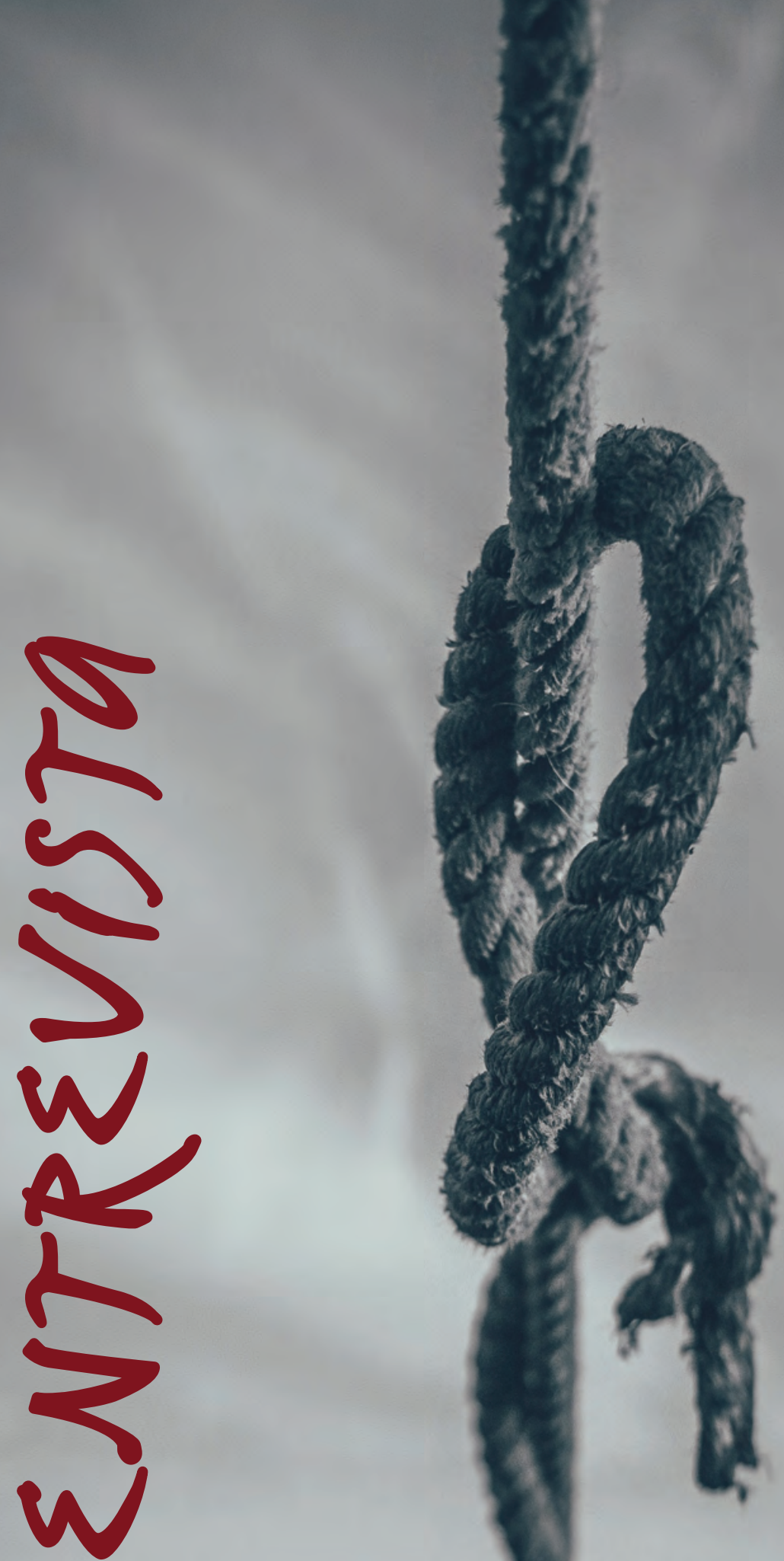


\title{
LITERATURA, VIOLÊNCIA E FÚRIA PLÁSTICA: ENTREVISTA COM MAFALDA IVO CRUZ
}

\author{
LITERATURE, VIOLENCE AND \\ AESTHETIC FURY: INTERVIEW WITH \\ MAFALDA IVO CRUZ
}

Bruno Mazolini de Barros ${ }^{1}$ Samla Borges Canilha ${ }^{2}$

Mafalda Ivo Cruz nasceu no final da década de 1950, em Lisboa. A escritora, que conta com formação completa como pianista no Conservatório Nacional de Lisboa, publicou, em Portugal, os seguintes romances: Um requiem português (Editorial Presença, 1995), A casa do diabo (Dom Quixote, 2000), O rapaz de Botticelli (Dom Quixote, 2002, Prémio PEN Club de Fiç̧ão), Vermelho (Dom Quixote, 2003, Grande Prémio de Romance e Novela da Associação Portuguesa de Escritores - APE), Oz (Dom Quixote, 2006), O cozinheiro alemão (Relógio D’Água, 2008) e Pequena Europa (Mariposa Azual, 2016). Além disso, Cruz participou de projetos como o Vozes e olhares no feminino (Edições Afrontamento, 2001), com o conto "Uma carta a Fátima", a coletânea de narrativas Contos policiais (Porto Editora, 2008), com "A Colina", e o livro Emma (Cavalo de Ferro, 2004), elaborado em colaboração com a artista plástica Joana Villaverde; neste, a autora produziu textos para as ilustrações de Villaverde. A escritora atua também como crítica literária - atividade com a qual contribuiu para o popular jornal Público entre os anos de 1999 e 2005 e para periódicos como Expresso, Rodapé e Colóquio/Letras.

Sua produção se destaca por uma densidade formal resultante, principalmente, da fragmentação textual, da não linearidade temporal e da variedade de vozes - construção que concorda com personagens de mente caótica e complexa. De temáticas variadas, as narrativas se caracterizam também por diversas interrupções, repetições e sobreposições espaciotemporais que dão poeticidade aos textos. 
Nesta entrevista, conduzida em novembro de 2017 e que explicita um pouco da peculiaridade dessa voz literária portuguesa, Mafalda Ivo Cruz trata principalmente do ofício da escrita e da configuração de seus romances.

Pergunta: Como é para a senhora ser mulher portuguesa no século XXI? De que maneira essa forma de ser e estar no mundo é definitiva ou não em sua literatura?

Mafalda Ivo Cruz: Saída em duas gerações de uma condição de humilhação sistemática, a mulher portuguesa do século XXI tem um comportamento que acompanha o dos outros países da Europa e do Ocidente. Identifica-se com a imagem de uma mulher livre na sexualidade, na política, etc. De especificamente português, vejo o Salazarismo. Como as outras ditaduras de direita, o Salazarismo definiu-se a partir da tradição na sua proposta ideológica. Quis ser português na sua essência.

Não saberia agora aprofundar o que possa significar ser português. Na minha experiência, talvez ser um pouco mais tolerante, mais emotivo, o que é um paradoxo; mas a verdade é que o regime salazarista também se autointitulava de regime de brandos costumes.

Hoje já ninguém fala de Salazar, já ninguém pensa nisso, no entanto, não foi há tanto tempo assim, ainda há reminiscências. Houve, por exemplo, agora no mês de outubro, o acordão do Juiz Neto Moura no Tribunal da Relação Porto, que evocou, numa sentença, as leis bíblicas, referindo à lapidação da mulher que comete adultério, ou ainda uma lei portuguesa de $1886 .{ }^{3}$ Sim, é extraordinário. Talvez seja um sintoma do medo que poderão sentir os homens em face da liberdade das mulheres nos dias de hoje.

Claro que a antiga condição da mulher portuguesa, que vigorou até aos anos de 1970, não foi uma criação de Salazar. Mussolini também idealizou a mulher como a mãe casta e lutadora, que obedece ao homem. Este dever de obediência, textualmente assim, lembro-me de ouvir falar dele como de uma coisa normal. $\mathrm{O}$ mesmo em relação à Petain, ${ }^{4}$ que decretou o Dia da Mãe em França naquela época, dia 8 de dezembro, dia de Nossa Senhora da Conceição. Ele tinha uma grande admiração por Salazar. Em geral, esses regimes limitaram-se a conservar e a transformar em doutrina a visão arcaica que hoje só os fundamentalistas católicos admitem.

A família portuguesa debaixo de Salazar parecia uma caricatura. Para nos apercebermos disso, basta dar uma vista de olhos pelos livros da chamada "instrução primária", segundo a linha do Ministério de Educação da época, que durou, como já disse, até aos anos de 1970.

Lembro-me de ler, nos anos de 1960, os romances de uma autora, para os nossos dias, exótica: Berthe Bernage (1886-1972). Portugal era, nessa altura, um país francófilo. A minha avó, que me tinha lido alto a lite- 
ratura infantil da Condessa de Segur, ${ }^{5}$ passou a oferecer-me um pouco mais tarde os livros da Berthe Bernage. Um deles contava a história de uma mulher "muito católica", como a minha avó dizia - querendo significar alguém respeitável -, que casava com um artista: no caso dela, um pintor. Nesse tempo, a imagem mais icónica do artista, artista esse que, ao contrário de Picasso - a success story -, era um conservador absoluto e, por isso, um homem honrado que só conseguia vender muito pouco. Esses dois, portanto, o artista honestíssimo e a jovem de boa família (boa família significa aqui, mais uma vez, família católica) têm juntos sete filhos criados a muito custo, no meio de uma grande paixão. Eram Brigitte e Olivier Hauteville. Seguem-se então romances ${ }^{6}$ que representam as fases da vida de uma mulher católica, apaixonada e lutadora, tudo o que a minha avó foi. A minha avó casou com um compositor monárquico.

Se eu pensar bem - e isto é bastante horrível, mas bom também - é como se estivéssemos seguindo uma sucessão de camadas arqueológicas, em que, num registo muito diferente, pode projectar-se um pouco da violência da vida e amores de uma mulher no quadro do romance $\mathrm{O} z$. Gertrud, a personagem, é a mulher de um artista, Oz, e submete-se aos seus demónios interiores (ao contrário de Olivier, Oz, é claro, tem demónios interiores).

Um paralelo indecente da minha parte. No entanto, há qualquer coisa de verdadeiro, mesmo se a minha avó era uma figura tão luminosa que conseguia transcender todas as contradições, ela e o meu avô foram de facto muito felizes. Mas trata-se de um corpo de doutrina que chegou até mim, penso que não me estou a enganar.

Devo dizer também que nunca foi a condição da mulher que me levou a escrever, não sinto que seja esse o meu papel. O que me leva a escrever é a experiência estética.

Pergunta: Considerando esse ponto anterior, qual é o motivo da presença constante da violência contra a mulher nos seus romances? Isso é explícito em $\mathrm{O} z$, como já comentado acima, em que o assunto está no mote da narrativa. No entanto, esse tópico aparece também, de alguma forma, em todas as narrativas: em Um requiem português, nas agressões constantes a Maria da Luz; em Vermelho, na violência também psicológica contra Isaura. Há sempre uma personagem feminina que sofre algum tipo de agressão por um homem.

Mafalda Ivo Cruz: Gertrud, de $\mathrm{Oz}$, nunca perde o seu rumo. Digo o "seu" porque, apesar de se tratar de uma situação criada a partir do inconsciente, isso representa uma escolha, uma provocação autodestrutiva radical. É o que ela quer (quer a provocação), embora não seja assim tão simples.

A Maria da Luz, personagem secundário do Requiem português, é diferente. A Maria da Luz vive uma catástrofe com o capitão, um longo desastre do qual apenas consegue sair viva. Nunca antes tinha analisado estas coisas, nunca tinha pensado nelas assim. 
No Vermelho, a Isaura partilha a perversidade do parceiro. Joga, pressente-o, manipula-o, mas quem tem sempre a palavra final é ele. Quando a pressão psicológica toma um carácter fabuloso, há uma transição: é como se o narrador mudasse de voz, passasse a falar em sonhos; o que ele diz é inacreditável, por isso apenas ronda as palavras, não se atreve. Aí surge um tom menor no livro. O pesadelo começa e depois acaba. Quando acaba, seguimos em frente sem saber o que se passou, se aquilo foi verdade. Claro que não é um livro realista. É um livro que vive da linguagem, da fúria, da violência plástica.

Pergunta: Ainda sobre a violência, ela está, em geral, em seus romances, associada à loucura, traços que são apresentados como constituintes do ser humano. A senhora apresenta isso como uma crítica ou, por exemplo, como uma argumentação a favor de um determinado ponto de vista?

Mafalda Ivo Cruz: Nunca apresento nada como crítica. Apresento "outra coisa", a "consequência" de um determinado estado das coisas, talvez. Como lhes disse, é a primeira vez, agora, aqui a responder-lhes, que penso um livro meu desse modo.

A loucura está na sombra de todo o ser humano. Está lá sempre. Ora é evidente, ora não é. A respeito da loucura apenas a constato. Cansa-me, é tudo.

Pergunta: Que efeitos a senhora busca com a utilização de diversas referências artísticas, e como propõe-se a trabalhar com isso nos seus textos? São recorrentes, por exemplo, as referências musicais nos romances. $\mathrm{O}$ fato de ser pianista foi definitivo para isso?

Mafalda Ivo Cruz: O meus pais eram músicos, os meus irmãos também, o meu avô e a minha avó, como já lhes disse. A minha avó foi, na sua juventude, grande amiga de Almada Negreiros, foi futurista, entre outras coisas, pensava em arte, escrevia muito bem.

Como diz Eduardo Lourenço, em Da pintura, "as famílias dos próprios artistas que naturalmente vivem, permanentemente, em função de um mundo invisível de formas de onde a sua própria inspiração se alimenta [...], ou para fazer das suas futuras criações um eco e um comentário perpétuo".7

Ou mais adiante, citando Proust "la musique maidait à descende en moi même, à y dècouvrir du nouveau". "É infinitamente verdade, temos que descer profundamente até onde o inconsciente se manifesta, se impõe, faz por aparecer ou desaparecer isto e aquilo por razões de ritmo, de medida, abstractas.

Sobre a utilização de textos ou material de outros na minha escrita, ela não teria sentido de outra maneira.

Se não pudesse abordar o que realmente me interpela, a coisa em si do que me interpela; se não pudesse viver com a "mente" dos outros a um 
nível muito profundo, provavelmente nunca teria escrito nada. Por assim dizer, nunca tratei da "vida real".

Sim, isso é também o resultado de uma formação de intérprete.

Pergunta: Dentre essas diversas referências artísticas, há a reincidência de menções a obras barrocas em $\mathrm{O} z$, por exemplo. Há um motivo especial nessas escolhas? No entanto, o efeito chiaroscuro, assim como outras tensões, como entre o sagrado e profano, estão presentes, de diversos modos, e são largamente utilizados em seus romances.

Mafalda Ivo Cruz: O corpo dos meus livros está aí. No chiaroescuro, na leitura das tensões, como dizem, entre o sagrado e o profano. $\mathrm{O}$ profano será um segundo território, penso eu.

Pergunta: Pensando a sua obra cronologicamente, de certa maneira, há um afastamento do contexto português nos romances mais recentes. Por exemplo, no primeiro, Um requiem português, a referência temporal é a ditadura salazarista, assim como em A casa do diabo; em Vermelho, tem-se o contexto da colonização em África ao se falar do passado da família do narrador-protagonista. Com o tempo, a impressão que se tem é de que deixa de falar de Portugal especificamente para falar da opressão em um escopo maior, como de certa forma ocorre neste último romance, Pequena Europa.

Mafalda Ivo Cruz: Digamos que sempre tratei Portugal por tu, sem grande respeito. ${ }^{9}$ Portugal é o lugar onde nasci, não o que eu sou.

Pergunta: Qual é o motivo da escolha de uma ambientação que propicia a relação do romance $\mathrm{O} z$ a um contexto soviético ou de Leste Europeu, por exemplo? Isso ocorre também em Pequena Europa.

Mafalda Ivo Cruz: Essa atmosfera do Leste Europeu estava a surgir nessa altura. Era praticamente uma necessidade. Foi uma exposição da pobreza que os ocidentais sentiam de outra maneira, por isso existia esse apelo, pela exposição de vidas e sociedades "avariadas", cheias de dores e de repetições compulsivas. E, ao mesmo tempo, um poder de inocência, como que final.

Pergunta: Em Pequena Europa, a senhora aproxima a narrativa de um estilo ensaístico. O que foi definitivo para essa escolha na escrita no romance?

Mafalda Ivo Cruz: O que existiu de definitivo foi a experiência artística sempre a confrontar o meu próprio caminho, a minha própria memória com as dos outros. Cruzar todas as vozes, aí está o caudal da experiência humana. Não saberia ir mais longe.

Pergunta: De que modo vê-se na tradição literária portuguesa? Tem alguma ideia de pares ou de pertencimento a uma linhagem ou tradição literária? Isso afeta a sua escrita de algum modo, ou vê-se como artista em um campo maior ou mesmo diferente? 
Mafalda Ivo Cruz: Não me vejo na tradição literária portuguesa, é certo que não. Nasci no canto mais ocidental da Europa, onde há gente muitíssimo interessante, é verdade.

Vejo-me como artista num campo diferente, não como escritora.

\section{NOTAS}

1 Doutorando em Teoria da Literatura na PUCRS, bolsista CNPq. Participante do grupo de pesquisas Cartografias narrativas: redes e enredos de subjetividade, PUCRS, no qual se estuda romances portugueses publicados a partir do ano 2000. Contato: brunomazolini@ gmail.com

2 Doutoranda em Teoria da Literatura na Pontifícia Universidade Católica do Rio Grande do Sul (PUCRS), bolsista CNPq. Mestra em Teoria da Literatura pela mesma instituição. Bacharela em Letras - Português/Literaturas pela Universidade Federal de Santa Maria (UFSM). Integrante do projeto de pesquisa Cartografias narrativas em língua portuguesa: redes e enredos de subjetividade. Contato: samlaaborges@gmail.com

3 O acordão, do qual o juiz Neto Moura foi o relator e que veio a público em outubro de 2017, foi proferido, na verdade, em outubro de 2016, no Tribunal da Relação do Porto.

4 Henri Philippe Benoni Omer Joseph Pétain, conhecido como Marechal Pétain (18561951). A comemoração, que já ocorria em algumas províncias, passou a ter uma abrangência nacional a partir de Pétain.

5 Escritora russa de literatura infanto-juvenil Sophie Feodorovna Rostopchine (17991874).

6 Série de romances do ciclo Brigitte.

7 LOURENÇO, Eduardo. Da pintura. Transcrição, Organização e Prefácio de Barbara Aniello. Lisboa: Gradiva Publicações, 2017, p. 39.

8 LOURENÇO, Eduardo. Da pintura. Transcrição, Organização e Prefácio de Barbara Aniello. Lisboa: Gradiva Publicações, 2017, p. 40.

9 Em Portugal, o uso da segunda pessoa do singular denota familiaridade, informalidade. 